\title{
In children with moderate dehydration, oral rehydration reduced ED stay and staff time compared with intravenous rehydration
}

\author{
Atherly-John YC, Cunningham SJ, Crain EF A randomized trial of oral vs intravenous rehydration in a pediatric \\ emergency department. Arch Pediatr Adolesc Med 2002;156:1240-3.

\section{QUESTION: Is oral rehydration therapy (ORT) as effective as intravenous therapy (IVT) for moderate dehydration in children with acute gastroenteritis?}

\section{Design}

Randomised (unclear allocation concealment*), blinded (data collectors),* controlled trial with follow up 2-4 days after discharge.

Source of funding: not stated.

For correspondence: Dr S J Cunningham, Jacobi Hospital, Bronx,

NY,USA.sjcny@gis.ne

\section{Setting}

A paediatric emergency department (ED) in an urban public hospital in Bronx, New York, USA.

Oral rehydration therapy (ORT) v intravenous therapy (IVT) for moderate dehydration in children with acute gastroenteritist

\begin{tabular}{lrrc} 
Outcomes & ORT & IVT & $\begin{array}{l}\text { Mean difference between } \\
\text { groups ( } 95 \% \mathrm{CI})\end{array}$ \\
$\begin{array}{l}\text { Length of emergency } \\
\text { department stay }(\mathrm{min})\end{array}$ & 225 & 358 & $133(47$ to 219$)$ \\
\hline Staff time (min) & 36 & 65 & $29(3$ to 56$)$ \\
\hline
\end{tabular}

†Abbreviations defined in glossary; mean difference and $\mathrm{Cl}$ calculated from data in article.

\section{COMMENTARY}

This small randomised controlled trial by Atherly-John et al compared the efficiency of ORT and IVT for children with moderate dehydration who presented to a paediatric ED. 2 systematic reviews have provided evidence that the failure rate is sufficiently small, and that ORT is still a valid first option. ${ }^{1-2}$ Additionally, treatment failure only means that one switches to IVT.

Although evidence suggests that failure rates of ORT and IVT are not clinically different, existing trials were designed to test efficacy rather than equivalence. Therefore, although we can conclude that there is no evidence of a treatment difference, we cannot claim that the treatments are equivalent. ${ }^{3-4}$

Despite substantial evidence and existing guidelines by professional bodies to promote ORT, ${ }^{5}$ recent survey data suggest that many paediatricians in the developed world are not adopting this approach. ${ }^{6}$ One reason is the perception that ORT is more time consuming than IVT. ${ }^{7}$ In addition, uncertainty may exist about the appropriateness of ORT among the range of children presenting with moderate dehydration, particularly those with vomiting. ${ }^{6}$

The study by Atherly-John et al rebuts the sceptics of ORT. The finding that ORT results in shorter ED stays and uses less staff time should encourage the sceptics to change their practice and use ORT. The finding that parents of children who received ORT rated all aspects of their care higher than those who received IVT provides further support for the use of ORT.

Terry Klassen, MD Lisa Hartling, MSc University of Alberta Edmonton, Alberta, Canada

1 Gavin N, Merrick N, Davidson B. Efficacy of glucose-based oral rehydration therapy. Pediatrics 1996;98:45-51.

Bellemare S, Hartling L, Wiebe N, et al. Oral rehydration versus intravenous therapy for treating dehydration due to gastroenteritis in children. Pediatr Res 2002;52:87A.

Ware JH, Antman EM. Equivalence trials. N Engl J Med 1997;337:1159-61.

Djulbegovic B, Clarke M. Scientific and ethical issues in equivalence trials. JAMA 2001.285:1206-8.

5 Practice parameter: the management of acute gastroenteritis in young children. American Academy of Pediatrics, Provisional Committee on Quality Improvement, Subcommitte on Acute Gastroenteritis. Pediatrics 1996:97:424-35.

6 Ozuah PO, Avner JR, Stein RE. Oral rehydration, emergency physicians, and practice parameters: a national survey. Pediatrics 2002;109:259-61.

Reis EC, Goepp JG, Katz S, et al. Barriers to use of oral rehydration therapy. Pediatrics

8 Santosham M. Oral rehydration therapy: reverse transfer of technology. Arch Pediatr Adolesc Med 2002;156:1177-9.

\section{Patients}

34 previously healthy children aged 3 months to 17 years (mean age 5 y, 55\% girls) who had signs and symptoms of acute gastroenteritis for $<1$ week and met $\geq 4$ standard criteria for moderate dehydration. Exclusion criteria were chronic illness, severe dehydration or shock, protracted vomiting, absent bowel sounds, no accompanying guardian or contact telephone number, and requirement of intravenous access for reasons other than hydration. All patients were included in the analysis.

\section{Intervention}

18 children allocated to ORT were given a commercial oral electrolyte solution by their parent or guardian $(5$ $\mathrm{ml}$ every $5 \mathrm{~min}$ for those $<4$ years of age and $10 \mathrm{ml}$ for those $\geq 4$ years of age). If no vomiting occurred during the first hour, the volume was doubled. If the child vomited, oral fluids were withheld for 30 minutes and then restarted at the initial rate. Children who vomited $\geq 3$ times after initiation of ORT were started on IVT. 16 children allocated to IVT were given an initial bolus of isotonic sodium chloride solution, $20 \mathrm{ml} / \mathrm{kg}$, over 30 minutes and a second bolus if necessary. After this, children $\geq 2$ years of age were given $5 \%$ dextrose in $0.45 \%$ saline, and those $<2$ years were given $5 \%$ dextrose in $0.33 \%$ saline. The dextrose-saline solution was administered at a rate of 1.5 times daily maintenance. During maintenance therapy, children were given the same ORT as the ORT group.

\section{Main outcome measures}

Main outcome was duration of ED stay, with discharge decisions made by the attending physician according to reversal of presenting signs and symptoms and cessation of vomiting. Secondary outcomes included staff time for patient care, admission rates, and relapse after discharge.

\section{Main results}

Analysis was by intention to treat. The ORT group had shorter ED stays and required less staff time than the IVT group (table). The groups did not differ for admission rates $(11 \% v 25 \%, \mathrm{p}=0.2)$, and no children in either group relapsed.

\section{Conclusions}

In children who presented to the emergency department (ED) for moderate dehydration associated with acute gastroenteritis, oral rehydration therapy (ORT) reduced length of ED stay and staff time compared with intravenous therapy (IVT). ORT and IVT did not differ for hospital admissions or relapse after discharge.

*See glossary. 